\title{
Aspectos do quotidiano no transporte de escravos no século XVII: do sertão africano à costa americana
}

\author{
MARIA DO ROSÁRIO PIMENTEL*
}

Resumo: Partindo da realidade específica que é o tráfico negreiro, a mais longa e dramática migração forçada da História da Humanidade, procuramos detectar aspectos do quotidiano, através de uma leitura transversal que, no caso do transporte de escravos, passa, a maior parte das vezes, pelos testemunhos daqueles que representam o domínio senhorial.

Abstract: In our text we deal with the reality of the slave trade which we consider the longest and most dramatic forced migration of World History. Therefore, we try to reveal aspects of everyday life, through a cross cultural interpretation which, in the matter of slave trade, is based, above all, on the testimonies of those who exercised the dominion.

Palavras-chave: Escravatura. Tráfico de escravos. Negreiros.

Key words: Slavery. Slave trade. Slave traders.

Vindos diretamente dos portos coloniais americanos ou dos empórios comerciais europeus, os navios negreiros chegavam à costa africana alvoroçando a vida das populações locais. Chegavam carregados, até não poderem mais, de mercadorias de troca, sem falsas intenções, contando à partida com a adesão das sociedades africanas, onde a escravidão era uma instituição naturalmente aceite. Traziam consigo novidades, riquezas de outras terras, exotismos de outros lugares; produtos que o africano valorizou e a que se habituou, em alguns casos, até à dependência.

Professora da Faculdade de Ciências Sociais e Humanas da Universidade Nova de Lisboa, Portugal. E-mail: rosariopcpimentel@mail.pt 
Dos seus porões saíam objetos de ferro, contaria de variadas cores, barretes e manilhas ou búzios e conchas, ali aceites como moeda. Saíam armas e munições, mais eficazes que as dos naturais, cuja força era uma garantia de poder num mundo convulsionado por guerras contínuas. Saíam os tecidos, os rolos de tabaco, os vinhos e aguardentes, nomeadamente a "giribita" brasileira, tão especiais neste trato. Saíam os fardos de roupa usada, de onde sobressaíam os chapéus e os uniformes de vistosos galões, que tanta influência exerciam nos africanos de maior prestígio social, na medida em que lhes permitiam uma certa identificação com a grandeza e o heroísmo ditado pelo modelo europeu. ${ }^{1}$

Tudo os negreiros se apressavam a expor em mercado assim que chegavam. Para o efeito, o próprio capitão do navio mandava construir, no descampado mais próximo do embarcadouro, um barracão de madeira - o "quibanga", como lhe chamavam os congoleses -, que depois também viria a servir para recolher os escravos. O toque do sino era o sinal de que tudo estava a postos para se iniciarem as transações.

Ali acorriam os povos das vizinhanças, os mercadores por conta própria, os que tinham casa de negócio para o efeito e, sobretudo, um grande número de intermediários. A estes últimos, com a expansão do tráfico para o interior, cabia a tarefa da concentração dos escravos nos portos marítimos, de modo a permitir, tanto quanto possível, uma carga pronta a embarcar sem demoras nem prejuízos. Eram os mercadores sertanejos, os "comboieiros", designados em certas regiões por "funidores", noutras por "tumberos" ou, ainda, "pombeiros" na região de Angola e "tangomaos" ou "lançados" na Guiné. Eram eles que viajavam pelos longínquos presídios e efetuavam a primeira compra dos escravos aí existentes.

Por norma, o europeu não se embrenhava no sertão com esse fim. Na generalidade, estes intermediários eram indivíduos negros ou mulatos livres, alguns treinados para exercerem essa função. Excetuavam-se os "lançados", expressão que no século XVI se reportava apenas aos brancos fugidos da metrópole ou fixados no ultramar sem autorização, que adotavam os usos e costumes indígenas e monopolizavam a concentração e distribuição de mercadorias nos portos africanos; comercializavam-nas sobretudo com mercadores estrangeiros, o que levou a coroa a insurgir-se contra a

1 Cf. PIMENTEL, Maria do Rosário. Viagem ao fundo da consciência. A escravatura na Época Moderna. Lisboa: Colibri, 1995, p. 67-73. 
sua atividade. Com o tempo, o termo passou a englobar também negros e mulatos que participavam nestas atividades comerciais. ${ }^{2}$

À chegada dos navios negreiros, os intermediários afluíam à costa para se abastecerem das mercadorias secas e molhadas, destinadas ao comércio e aprontarem os "comboios" de carregadores que as iriam transportar. Os carregadores, cerca de cem por cada "comboio", ${ }^{3}$ eram requisitados ao capitão-mor, que tinha por obrigação fornecê-los em beneficio do comércio e que, por sua vez, os exigia aos próprios chefes indígenas - os "sobas" - que os seleccionavam de entre os naturais do país. Nem sempre era fácil aos sertanejos obter das autoridades estes homens que eram vitais para a execução do que se propunham. Na maior parte dos casos, só os conseguiam através de uma insistente negociação, se bem que esta prática estivesse interdita àqueles funcionários da coroa. ${ }^{4}$

Assim, munidos de guardas e carregadores, que aos ombros conduziam os fardos de fazendas, os instrumentos de prisão e marcação dos escravos, a alimentação - somente a indispensável partiam os "comboieiros" para o interior, onde o mais pequeno sinal da sua presença fazia recrudescer as práticas de aprisionamento e transformava a região num campo de luta e caça ao homem. Nessas alturas, intensificavam-se as guerrilhas e os assaltos, surgiam novos delitos e acusações, multiplicavam-se os ódios e as desconfianças. A coberto da noite, incendiavam-se as choupanas para, na fuga desvairada, se apanharem os sobreviventes às chamas. Nos caminhos, construíam-se armadilhas, armavam-se ciladas em que caíam os mais desprevenidos. Aos crimes de morte, roubo ou adultério, que tradicionalmente já eram castigados com a venda do infractor como escravo, juntavam-se agora outras faltas ligeiras. E os processos de prova eram verdadeiros ardis, feitos à base de venenos, ferros em brasa e águas a ferver, dos quais resultava sempre a condenação do acusado e da sua família. ${ }^{5}$

2 CARREIRA, António. Cabo Verde. Formação e extinção de uma sociedade escravocrata (1460-1878). Porto: Centro de Estudos da Guiné Portuguesa, 1972, p. 47-62; MENDES, Luís António de Oliveira. Discurso Académico apresentado à Academia Real das Ciências a 12 de Maio de 1783. In: CARREIRA, António. As Companhias Pombalinas. 2. ed. Lisboa: Presença, 1983, doc. n. 11, p. 379.

3 Mendes, loc. cit., p. 379, nt. b; J. F. de Almeida Prado aumenta este número ao referir que nesses "comboios" figuravam de 400 a 600 homens, chamados "mocazembos" ou negros de carga (PRADO, J. F. de Almeida. O Brasil e o Colonialismo Europeu. São Paulo: Nacional, 1956, p. 71).

4 CORREAA, Elias Alexandre da Silva. História de Angola [1792?]. 2. ed. nota prévia de Dr. Manuel Múrias, Lisboa, 1937, p. 36-37. v. 1.

5 Pimentel, op. cit., p. 65-67. 
Contudo, grande parte dos escravos eram prisioneiros de guerra capturados em lutas movidas pelo espírito de conquista territorial ou simplesmente suscitadas com o intuito de adquirirem prisioneiros para venda. Inclusivamente, os mercadores, para obterem o maior número de escravos, não se privavam de tecer intrigas junto dos régulos, adivinhos ou elementos a eles afeitos, aliciando-os com ofertas, a maior parte das vezes bebidas, com as quais os embebedavam. Os vinhos e aguardentes eram, aliás, um elemento importantíssimo neste processo de negociações - tão importante que o mercador levava já separada toda a bebida que devia ser distribuída como presente, talvez para a distinguir do vinagre, que ali corria no "mesmo paralelo", ou daqueles vinhos e aguardentes já alterados "com água pura ou salgada temperada com pimentões" para fortalecer a "fraqueza da sua ardência".

Esta inclinação dos homens da terra era aproveitada ao máximo pelos negociantes. Elias Corrêa comenta a este propósito que "sem entrevir a giribita repugnam os negros concluir os seus negócios", e conclui ser "uma felicidade" para os comerciantes do Brasil e da África terem "a inclinação dos habitantes a seu favor". Alucinados pela bebida, incitados à guerra, auxiliados pelas armas européias, facilmente os negros se entregavam a operações de razia, de onde resultavam muitos prisioneiros. O efeito depredatório destas guerras contínuas reflectia-se de tal modo na situação econômica das populações, que passaram a ter na escravização uma solução possível para a sua subsistência, o que os levava amiúde a vender os próprios familiares. Mas, igualmente, os vendiam ou penhoravam, na ânsia de adquirirem mercadorias ou no delírio da embriaguez.

No quadro das sociedades africanas, não só os criminosos, mas também os devedores insolventes eram punidos com a escravidão. Um condenado podia nomear alguém para sofrer por ele a sua pena. Porém, este direito estendia-se somente àqueles indivíduos que lhe estavam subordinados e tinha que englobar mais do que uma pessoa, variando o seu número consoante a gravidade do delito ou o montante da dívida. ${ }^{8}$ Não é de admirar, por isso, que se concedessem facilmente mercadorias a crédito, uma vez que o credor, mesmo que o devedor desaparecesse com a mercadoria, tinha sempre um modo de reaver o seu dinheiro. Os capitães negreiros tinham por norma conceder gêneros fiados aos agentes

Corrêa, op. cit., p. 39-40.

Idem, p. 40.

Mendes, loc. cit., p. 377. 
negros, aceitando unicamente como penhora os filhos ou parentes mais próximos. Este fato pressionava-os a cumprir os prazos do contrato e a trazerem o número de escravos ajustado. Desta maneira, se convertiam, segundo o autor anônimo do Bosquejo, "os fatores mais ternos do coração em instrumentos de crueldade e de injustiça", não poupando meio algum para pagar a sua fazenda.'

Alguns dos escravos que se encontravam presos no interior já estavam a ferros há muito tempo, por vezes anos a fio, à espera de quem os comprasse. Era grande a sua angústia e, quando as caravanas dos mercadores chegavam, manifestavam-se apreensivos quanto à sorte que os esperava. Testemunha Mungo Park, explorador inglês integrado num desses "comboios", que eles olhavam os traficantes com horror e insistentemente perguntavam qual o destino dado aos escravos que passavam a "água salgada". A firme persuasão em que estavam de que os brancos compravam os negros para comer ou para os vender a outros que os comiam fazia com que olhassem com incrível pavor a viagem até à costa. ${ }^{10} \mathrm{~A}$ sua perturbação era grande e os mercadores receosos de alguma fuga, revolta ou suicídio, mantinham-nos constantemente presos.

À medida que os iam comprando, agrilhoavam-nos dois a dois a uma corrente que, embora muito devagar, lhes permitia caminhar. Para maior segurança, dividiam-nos, depois, em grupos de quatro, que acorrentavam pelo pescoço. E, à noite, prendiamlhes ainda as mãos com argolas de ferro. Aos menos submissos, destinavam um grosso cepo onde ficavam presos pelas pernas ou, então, um tronco de madeira, aparelho que abria pelo meio, fechava com forte argola de ferro e tinha escavados orifícios por onde podiam passar o pescoço, os braços ou as pernas dos escravos, mantendo-os imobilizados.

Ao ato da compra, seguia-se a primeira marcação, com ferro em brasa, que lhes imprimia o sinal do mercador para poderem ser reconhecidos em caso de fuga. ${ }^{12} \mathrm{E}$ quando o número de escravos era já suficiente, iniciava-se a penosa marcha em direcção ao litoral, que poderia durar largos meses. Os escravos caminhavam acorrentados, com o braço direito preso nos anéis dos "libambos" e o pescoço entalado nas gargalheiras de ferro ou na forquilha das prisões de pau e correias entrelaçadas. A cada passo os mais resistentes arrastavam consigo aqueles a quem já iam faltando as for-

\footnotetext{
Bosquejo sobre o commercio em escravos. Londres: Ellerton e Henderson, 1821, p. 14.

Idem, p. 33.

"Idem, p. 33-34. Mendes, loc. cit., p. 379.

12 Mendes, loc. cit., p. 369.
} 
ças. E se, sob a vigilância atenta dos guardas, o andamento abrandava, ou se alguém se recusava a prosseguir, a autoridade do chicote anunciava que era necessário continuar e que só a morte dali os podia libertar.

Às costas levavam o "carapetal", saco que continha a ração que o mercador lhes destinava até chegarem a outro presídio, onde de novo se abasteciam. $\mathrm{O}$ excesso de peso, o cansaço e a debilidade obrigavam-nos desde logo a certas carências. Saliente-se o caso do sal que, por ser pesado, faltava na alimentação, tornando-a insípida e desagradável. Como também faltavam a pimenta e o azeite, condimentos tão a seu gosto, comiam somente para não morrer. À escassez aliava-se o mau estado dos alimentos, comprados já deteriorados - o que os tornava mais baratos - e a sua má confecção, uma vez que tudo era cozinhado à pressa, apenas "aferventados" em função do tempo do mercador e da distância a percorrer. $^{13}$

A água, só a bebiam quando se aproximavam dos charcos e lagoas. Por cama tinham o chão e as próprias folhas das árvores, nem a todos protegiam da cacimba que continuamente caía durante a noite, ensopando o único vestuário que possuíam ou o que dele restava. Uma fogueira era o seu único conforto, porém, insuficiente para atenuar os efeitos nefastos do orvalho e da falta de vestuário, que estavam na origem de muitas das enfermidades de que padeciam. As grandes febres chamadas "carneiradas", por exemplo, atribuídas aos efeitos da cacimba, eram significativas pela maneira como se propagavam e dizimavam os escravos em poucos dias. ${ }^{14}$

As horas de sono eram passadas numa modorra constante sob os gritos dos guardas que freqüentemente os acordavam com receio de algum levantamento, sugestionados pela crença de que os escravos conheciam uma erva capaz de amaciar e estalar o ferro das prisões. ${ }^{15}$

Chegavam aos portos marítimos já muito debilitados. Eram, então, permutados pela segunda vez. No entanto, os comerciantes continuavam a mantê-los presos com as mesmas correntes com que tinham viajado, ou fechavam-nos em pátios de altas paredes e devidamente apetrechados com correntes de ferro, argolas encastoadas, cepos de madeira e grilhões. À noite, tinham agora o privilégio de um telheiro ou armazém térreo, mas tão imundo que o

13 Idem, p. 381.

14 Idem, p. 390.

15 Idem, p. 381. 
cheiro que exalava, segundo o médico setecentista Francisco Damião Cosme, até fazia "delíquios e vômitos" a quem passasse defronte. E era aqui, continua o autor, "neste asquerosíssimo charco acrescentado continuamente com os escrementos da mesma infeliz gente", que se conservavam os escravos até serem comprados pelos capitães negreiros. ${ }^{16}$

No litoral, a alimentação do escravo, apesar de lhe adicionarem o sal necessário, que ali existia em abundância, continuava a ser escassa e de má qualidade. Só a fome os obrigava a comer uma refeição feita à base de "farinha ou mandioca podre ou cheia de mofo", de milho e feijão "corruptos", aos quais era adicionado, por vezes, algum peixe salgado já "velho e fedorento", conforme a descrição de Damião Cosme. ${ }^{17}$ Os negociantes, esperando a todo o momento a venda dos escravos, recusavam-se a gastar dinheiro com eles.

Mal alimentados, mal vestidos, torturados, sem cuidados médicos ou de higiene, pois apenas lhe era permitido irem em lotes lavarem-se ao mar, assim permaneciam por tempo indeterminado, acabando grande parte por morrer. Oliveira Mendes salienta, a este propósito, que a Luanda chegavam todos os anos cerca de dez a doze mil escravos, dos quais só eram transportados para o Brasil cerca de seis ou sete mil. Todos os outros acabavam por perecer, vitimados pelo cálculo econômico dos negociantes, que preferiam vê-los morrer a despender algum dinheiro e a ter certos cuidados com a conservação da sua saúde. ${ }^{18}$

Mas quando os negreiros se apresentavam para o negócio, a situação alterava-se ligeiramente. Nessa ocasião, os escravos eram sujeitos a um minucioso exame por parte dos compradores, que não se deixavam facilmente influenciar pelas qualidades apregoadas pelos vendedores. Procuravam assegurar-se da origem dos escravos, idade, condições físicas, temperamento e caráter, características importantes que podiam determinar decisivamente os preços. Faziam-nos correr, saltar, gritar; examinavam-lhes os dentes, os olhos, os músculos e órgãos genitais; observavam-lhes as atitudes e provocavam-nos com violência para descobrir se o ânimo correspondia às aparências. Tudo exigia uma observação atenta, porque os vendedores usavam de toda a astúcia para alterar estes dados a seu favor.

${ }^{16}$ COSME, Francisco Damião. Tratado das queixas endémicas, e mais fataes nesta conquista. Intr. do Prof. Luís de Pina. Sep. da "Studia". Lisboa, 1967, p. 143-144.

17 Idem, p. 147. Mendes, loc. cit., p. 382.

${ }^{18}$ Mendes, loc. cit., p. 383. 
Neste sentido, com o objetivo de lhes melhorar a aparência e impressionar o comprador, nos dias que antecediam a venda, os mercadores aumentavam-lhes a ração; esfregavam-nos com óleo de palma, que os tonava mais negros e luzidios; aos que já tinham barba, escanhoavam-nos bem e, como último ardil para os encarecer, friccionavam--lhes o rosto com pedra-ume, de modo a deixálo macio como se fossem imberbes. Sem o menor vestígio de barba à vista e ao tato, restava aos peritos negreiros recorrer ao processo de passar a língua pelo rosto dos negros, procurando assim detectar o que, de outra maneira, lhes escaparia. Por processo semelhante, através do sabor do suor, tentavam descobrir se o escravo tinha ou não contraído determinadas doenças. ${ }^{19}$

A escolha estava feita. O escravo dava entrada no barracão do traficante, onde iria esperar o momento do embarque. Na altura do pagamento dos direitos a que esta transação estava sujeita, sofriam nova marcação a fogo, no lado direito do peito, representando as armas do rei e do país a que passavam a pertencer. No peito, do lado esquerdo, no braço ou na perna, podiam ainda sofrer outra marca com o sinal do senhor que os negociava e transportava para o Brasil. ${ }^{20}$ Era um processo dolorosíssimo, feito com instrumento de prata incandescente, que se pressionava sobre papel engordurado na zona do corpo pretendida. A carne inchava com dor intensa e o estigma surgia, em relevo, para toda a vida.

Seguia-se o embarque com destino aos seus novos presídios de além-mar. Porém, antes de embarcarem recebiam o batismo em conjunto, com um hissope, muitas vezes já na praia, sem a mínima compreensão do que se estava a passar, pois a pressa de partir não permitia uma catequização conveniente. Falavam-lhes apenas de uma nova terra pertencente aos portugueses onde iriam aprender as coisas da Fé. ${ }^{2 f} \mathrm{E}$ posto este cuidado, suficiente para sossegar a consciência cristã dos capitães negreiros quando começavam a atirar cadáveres ao mar, procedia-se à passagem dos cativos para o navio. Era um momento difícil, em que os negros atormentados pela imaginação e pelo afastamento da costa, tentavam, num último esforço, libertar-se, procurando à custa de contorções desequi-

${ }^{19}$ CHAMBON, Jérome-Auguste. Commerce de I'Amérique par Marseille, par um citadin. Avignon: 1764. In: La traite des noirs au Siècle des Lumières (Témoignages de négriers), apresentados por I. et J. L. Vissière. Paris: Editions A. M. Métailié, 1982, p. 152-154; Prado, op. cit., p. 78-79; Bosquejo..., op. cit., p. 92.

20 Mendes, loc. cit., p. 369; Carreira, As Companhias..., op. cit., p. 136-138.

${ }^{21}$ Carreira, Cabo Verde..., op. cit., p. 260-261; MAURO, Frèdèric. L'Atlântique portugais et les esclaves (1570-1670). Lisboa: Sep. da Revista da Faculdade de Letras de Lisboa, t. 22, (2), $2^{\mathrm{a}}$ série, 1956, p. 35-36. 
librar as almadias ou, no momento em que subiam para o barco, aproveitar qualquer movimento em falso.

Embarcados em número muito superior àquele que o navio deveria transportar, eram amontoados na coberta ou sob a escotilha, mal se podendo mexer sem se incomodarem uns aos outros. $\mathrm{O}$ franciscano italiano Carli, que viajou a bordo de um desses navios carregado com 680 escravos, registou que iam "cruelmente acumulados" num espaço exíguo e imundo, onde homens e dejetos se misturavam de tal modo que o calor e os odores tornavam o ambiente intolerável. ${ }^{22} \mathrm{E}$ Elias Corrêa refere-se à "sordida imundície dos únicos panos com que mal se cobrem, e enxugam no corpo depois que a chuva, o sereno e o suor os molha; exalam um hálito insuportável, cujas partículas envolvidas" se juntam ao odor da transpiração de corpos enfermos, criando uma atmosfera onde se respira a morte "que os acomete e derruba com vontade". "A caridade desaparece" e "a sepultura é a obra de misericórdia mais ampla que se lhes administra". ${ }^{23}$

Aí tudo lhes faltava. A alimentação continuava a ser má e insuficiente, fermentada pelo calor e pelo azebre das caldeiras de cobre em que era cozinhada. A água, escassa, era saloba, alterada pela má qualidade do vasilhame. A pouca ou nenhuma higiene, juntamente com o intenso calor e a umidade salitrosa, ateavam as epidemias de que nem os marinheiros escapavam. O próprio ar, pouco ou nada ventilado, tornava o ambiente dos porões denso e pestilento; tal como a luz, entrava apenas pelas grades da escotilha, ou por uma ou outra fenda. Os capitães dos navios tinham consciência de quanto esta situação era prejudicial. E, querendo de algum modo minimizar as perdas, mais por interesse do que por humanidade, entre outras medidas, mandavam limpar e esfregar duas vezes por semana a coberta com vinagre e permitiam que os escravos, divididos em grupos, viessem a ferros até ao convés para receber ar fresco. Nessas ocasiões, davam-lhes uma porção de aguardente e, para fazerem algum exercício, obrigavam-nos a cantar e a dançar. Recomendavam, igualmente, que nos dias quentes e calmos, se prendesse no cesto da gávea uma manga de pano que, passando pela grade da escotilha, renovasse o ambiente. ${ }^{24}$ Todas essas providências eram, no entanto, apenas um esforço que na prática se revelava inútil para afastar o ar doentio e travar o avan-

\footnotetext{
Mauro, op. cit., p. 37-38.

Corrêa, op. cit., p. 57.

${ }^{24}$ Mendes, loc. cit., p. 384-385.
} 
ço das epidemias que os alimentos estragados, a ardência do clima e a imundície favoreciam.

Previa-se que a duração de uma viagem de Angola a Pernambuco, com condições favoráveis, era de trinta e cinco dias, à Baía quarenta e ao Rio de Janeiro cinqüenta. ${ }^{25}$ Mas se o navio ficava preso nas calmarias equatoriais, o percurso até ao Recife podia durar cinqüenta dias. Quanto mais longas fossem as viagens, piores se tornavam. Aquelas embarcações que iam da Guiné e da região de Daomé para a Baía beneficiavam de viagens mais rápidas. Nas das outras regiões, que, de preferência, se dirigiam para o sul do Brasil, os escravos padeciam a mais longa, cruel e mortífera travessia do oceano a que mais vítimas e maiores tragédias provocava. Elias Corrêa descreve a experiência que viveu na sua viagem para o Rio de Janeiro, em que os mantimentos e a aguada embarcados foram de tal modo preteridos pelo embarque de um maior número de escravos que, ao vigésimo dia de mar, já só era distribuída meia ração de água, chegando a situação ao ponto de se recusarem os remédios aos doentes pela sua falta. Quando aos sessenta dias de viagem se avistou terra, foram obrigados a aportar à capitania do Espírito Santo por falta total de mantimentos. Todavia, "a farinha de pau comprada neste porto para suprir a que o navio deixou de embarcar, estava tão podre e cheia de bicho que causou uma epidemia terrível e muitas mortes". ${ }^{26}$

Morriam não só vitimados pelas doenças, mas também devido ao desespero em que se encontravam e que os levava, na primeira oportunidade, ao suicídio. Neste ato, acontecia arrastarem consigo para o mar os seus companheiros de ferros e, por vezes, até os tripulantes do navio, dando assim resposta ao ódio que os minava. O seu desejo de morrer era tão forte que, faltando-lhes outros meios, recusavam-se a comer. Nestes casos, se mesmo depois de castigados mantinham a sua recusa, abriam-lhes a boca à força e obrigavam-nos a engolir os alimentos. ${ }^{27}$ Este procedimento dos escravos era acompanhado, com frequência, por manifestações doentias de caráter psicológico que designavam por "banzo" e apresentavam como principal sintoma uma nostalgia angustiante que, no dizer de Oliveira Mendes, constituía uma "paixão da alma a que se entregavam e que só dão por extinta com a morte". ${ }^{28}$

25 Lei de 28 de Março de 1684. In: Arquivos de Angola. Luanda, v. 2, ago./set. 1936, p. 315.

${ }^{26}$ Corrêa, op. cit., p. 57 , nt. 1 .

27 Bosquejo..., op. cit., p. 47.

${ }^{28}$ Mendes, loc. cit., p. 393-394. 
Os males eram tantos e tão grande o número de vítimas que algumas advertências e determinações legislativas foram sendo feitas, no sentido de procurar evitar, tanto quanto possível, o estado a que havia chegado o tráfico e de onde resultava morrerem muitos e chegarem ao Brasil "impiamente lastimosos os que ficavam vivos". ${ }^{29}$ A primeira dessas determinações, seguida de outras até à primeira metade do século XIX, ${ }^{30}$ foi a lei de 28 de Março de 1684, pela qual era estabelecida uma inspeção judicial, que limitava a carga de escravos às dimensões de cada navio e calculava os alimentos e a aguada de acordo com o número de escravos por navio e a distância a percorrer. ${ }^{31}$ A lei, porém, nada veio remediar, levando a ambição à degradação da inspeção judicial. Oliveira Mendes, em 1793, dizia que dela se abusava inteiramente. ${ }^{32} \mathrm{E}$, pela mesma altura, Elias Corrêa referia a inutilidade da sua existência, de tal modo se encontrava viciada. ${ }^{33}$

Esta situação resultava, em parte, de um deficiente projeto econômico no qual participavam não só os traficantes negreiros, mas também os funcionários do fisco, das alfândegas e, até, os próprios governadores, através de uma permissividade que revertia a favor dos seus interesses. Os traficantes de escravos, desde os negociantes do sertão aos capitães negreiros, pretendiam gastar o menos possível com a escravidão, mesmo que tal atitude acabasse por ceifar a vida de grande número dos seus escravos. Estas perdas já estavam incluídas nas suas previsões econômicas, razão pela qual embarcavam o maior número possível de escravos. Alguns autores, como Luís António de Oliveira Mendes, Francisco Damião Cosme e Elias Alexandre da Silva Corrêa, que se revelaram críticos mas não manifestamente contrários à escravidão e ao tráfico, tentaram chamar a atenção para este grave erro que, além de ser um crime horrendo e de demonstrar uma impiedade cruel, segundo eles, em nada favorecia o desenvolvimento dos estabelecimentos coloniais e demonstrava uma ignorância total quanto aos interesses dos mercadores.

Ao Brasil chegavam os mais resistentes a todas estas adversidades. O seu tormento, no entanto, ainda não tinha chegado ao fim e alguns haviam feito a travessia para acabar logo ali, em terra

29 Carta de Sua Majestade sobre a Lei das Arqueações, de 30 de Março de 1684. In: Arquivos de Angola, op. cit., p. 321.

30 Pimentel, op. cit., p. 76-82 e 320.

${ }^{31}$ Lei de 28 de março de 1684. In: Arquivos de Angola, op. cit., p. 313-320.

${ }^{32}$ Mendes, loc. cit., p. 405. Este autor faz referência a uma lei de 18 de março de 1684. Supomos que seja um erro e quisesse referir a lei de 28 de março de 1684.

33 Corrêa, op. cit., p. 55. 
alheia, destroçados pelos males que os vinham consumindo. Mesmo assim, alguns ainda se persuadiam de que agora a situação pudesse mudar, talvez porque haviam chegado à terra de que lhes tinham falado, talvez porque os vendedores procurassem, através desta idéia, incentivá-los a mostrarem-se mais ágeis perante os compradores, ou talvez ainda, porque os cuidados de preparação da "mercadoria" tinham, mais uma vez, disfarçado ligeiramente o seu sofrimento. Logo que desembarcavam, eram levados para o armazém do senhor ou da sociedade que tinha investido na sua vinda de África e a quem, na generalidade, pertencia também o navio. Aí eram divididos em lotes, para poderem ser vendidos consoante a sua compleição física. Aos mais debilitados, o "refugo" da carga, tentavam engordá-los minimamente ou, então, vendiam-nos barato a quem já tinha por negócio a sua engorda, para posterior venda a preço muito superior.

De pele oleada, barba raspada e, se necessário, a carapinha pintada, em lotes pela rua, mostrando o que valiam ou o que fingiam valer, redobrando os esforços para ficarem com os familiares ou conhecidos na posse do mesmo senhor, ali estava, pronta para passar mais uma vez de mão, uma leva de escravos, acabados de chegar de África.

34 Mendes, loc. cit., p. 386. 